\title{
A SURVEY ON ACCOUNTING FOR DERIVATIVES AND OTHER FINANCIAL INSTRUMENTS
}

\author{
Alan Reinstein, DBA, CPA \\ Wayne State University \\ Detroit, MI \\ Gerald H. Lander, DBA, CPA, CCA \\ University of South Florida \\ St. Petersburg, FL
}

\begin{abstract}
In response to the recent growth in the use of derivative financial instruments, the Financial Accounting Standards Board (FASB) recently required all companies to make certain classifications and disclosures for such "complex" financial instruments. Yet, the Securities and Exchange Commission (SEC) and the FASB now demand even further reporting requirements - including requiring companies to recognize the "fair value" (and resultant gains and losses) of their financial derivatives as well as make other "qualitative disclosures" of the potential risk of holding such financial securities. The provisions of the current and proposed standards will affect significantly virtually all types of companies, especially those using derivative instruments. Hence, those preparing and evaluating financial statements under this emerging set of standards must comprehend these new provisions. The paper first discusses the current standards relating to financial derivatives and other financial instruments; it then provides examples of "leading" disclosures of such financial instruments. Then, based upon the responses to a mail questionnaire, the paper discusses how key groups view potential SEC changes in accounting for derivatives. All four of the groups generally agree with the provisions of SFAS No. 119 and most favor the recently passed, increased reporting standards.
\end{abstract}

\section{A Survey on Accounting for Derivatives and Other Financial Instruments}

The 1990s witnessed a large growth in the issuance and use of new types of financial instruments. Prompted by such forces as the deregulation, internationalization and increased competition of financial markets, new financial instruments have emerged that contain debt, equity or hedging features. Briefly, companies can use such instruments as floating rate mortgages, stripped mortgage-backed securities and interest rate swap contracts to invest excess funds to "create" earnings or to hedge their portfolios from unexpected market activities. With the increased popularity of derivatives, the financial press also has reported significant losses by corporate and municipal end-users and dealers from the use of deriva- 
tives. Meanwhile, the Financial Accounting Standards Board (FASB) and the Securities and Exchange Commission (SEC) continue to grapple with the accounting and disclosure issues associated with derivatives. The purposes of this paper are to discuss current and proposed standards relating to derivatives and to present the results of a study that ascertain how key groups view SEC changes in accounting for derivatives.

Derivatives represent an interesting and important type of financial instrument, normally used to provide hedges against unexpected business risks, to lower borrowing costs or to increase income over that of other more conventional investments. Specifically, a derivative financial instrument's value is derived, at least in part, from the value and characteristics of one or more underlying assets, including commodities, securities or interest rates. For example, a company expecting the price of gold to reach $\$ 500$ an ounce within six months (when its current price is $\$ 450$ an ounce) may purchase a call option at, say, $\$ 40$ per ounce. If the price of gold reaches $\$ 500$, the company would exercise its call; otherwise, it loses only its $\$ 40$ call payment. (Note: the entity "betting" that the price of gold will not reach $\$ 500$ issues a put option, and such entities as the Chicago Mercantile Exchange bring the parties together.)

Many insurance companies, manufacturers, banks, not-for-profit organizations and other large and small companies such as Coca Cola and McDonald's have made large investments in derivative financial instruments. Per SEC Release Nos. 33-7250 and 34-36643 (1995), the worldwide notional/contract amounts for derivative financial and commodity instruments increased from $\$ 7.1$ trillion in 1989 to $\$ 62.1$ trillion in 1994 . Forbes magazine (1994) states that derivative transactions could have exacerbated many recent swings in stock prices, including the 1987 stock market crash. Furthermore, many losses in making such investments have occurred, reaching nearly $\$ 6$ billion in 1994 (Business Week, October 31, 1994). Many publicly held companies and governmental entities have suffered financial losses and embarrassment within the financial community from investing in derivatives - causing major FASB and SEC interest in the topic. The following sections provide an overview of current and proposed accounting and disclosure rules for derivative transactions.

\section{Current Rules for Derivative Financial Instruments}

Until 1995, only two FASB Statements provided specific guidance for accounting for derivatives and hedging transactions. FASB Statement No. 52, Foreign Currency Translation, addresses forward foreign exchange contracts, and FASB Statement No. 80, Accounting for Fulure Contracts, addresses exchangetraded future contracts. Recognizing, however, that these two standards only address a few of the many different types of derivative financial instruments used today, the FASB placed this issue on its active agenda. 
In 1996 the FASB's Statement (SFAS) No. 119, Disclosures About Derivative Financial Instruments and Fair Value of Financial Instruments, began requiring entities to separately disclose (a) information about derivative financial instruments held for trading and non-trading purposes and (b) categories of financial instruments, including classes of financial instruments, business activities, risks or any other categories that are consistent with the management of those instruments.

In 1998, the FASB issued a new Standard FASB No. 133, Accounting of Derivative Instruments and Hedging Activities, requiring entities to recognize derivatives as either assets or liabilities in their balance sheets and measure such instruments at their fair market values. Entities now recognize gains and losses resulting from changes in fair values depending upon the intended uses of the derivatives and whether they are designated and qualified for a hedging accounting relationship (i.e., that are "highly effective" to achieve offsetting changes in values or cash flows). Moreover, in 1997 the SEC issued FRN No. 48 requiring publicly traded entities to disclose additional information about the potential market risk associated with such derivatives.

Similar to the provisions of SFAS No. 105, 107 and 115, SFAS No. 119 (which require entities to recognize and disclose the risks of certain financial instruments - e.g., those declining in value - in the financial statements themselves or in the footnotes) defines a financial instrument as evidence of ownership interest in an entity or a contract that both:

(1) Imposes on one entity a contractual obligation to

a. Deliver cash or another financial instrument to a second entity, or

b. Exchange financial instruments on potentially unfavorable terms with the second entity, and

(2) Conveys to that second entity a contractual right to

a. Receive cash or another financial instrument from the first entity, or

b. Exchange other financial instruments on potentially unfavorable terms with the first entity.

Thus, one party to the transaction has a contractual right (e.g., to receive a security at a specific date), and the other has a contractual obligation (e.g., to deliver that security at that date). Such instruments include debt and equity securities. SFAS No. 119's provisions do not apply to investments in on-balance-sheet receivables and payables, including those deriving their values or contractually required cash flows from the price of some other security or index, including interest- and principal-only obligations, mortgage-backed securities and indexed debt instruments, as well as optional features embedded within on-balance-sheet receivables or payables, such as conversion and call features found in some convertible bonds. 


\section{Types of Derivatives}

Many types of derivatives can help manage risk in financial markets:

Options are securities transaction agreements tied to stocks, commodities or stock indices involving the right to buy or sell those instruments for agreed-upon sums.

Collateralized mortgage obligations pay a fixed interest rate at regular intervals, include mortgage-backed bonds that separate mortgage pools into short-, medium and long-term portions to provide flexibility in the repayment of investor capital.

Floating rate notes, including those relatively insensitive to interest rate changes, are debt instruments with a variable rate generally tied to prevailing short-term interest rates.

Futures Contracts (which are usually publicly traded) represent promises to buy or sell specific numbers of commodities, financial instruments or interest payments at a set price on a stipulated future date.

Indexed securities (also called structured notes) are highly customized shortterm debt instruments that allow investors to create and capitalize on short-term investment opportunities without liquidating or restructuring sound long-term investment positions. These "customized bonds" instruments are designed with yield features, with interest rates or principal amounts indexed to an unrelated indicator.

Interest-only strips (IOS) consist of the interest part of a mortgage security that was stripped into two parts; the other part is a principal-only strip. IOs receive cash flow from interest payments and offer an attractive yield as long as mortgage rates are stable or rising.

Principal-only strips (POs). As discussed above, $\mathrm{POs}$ receive cash flow from principal payments.

Inverse floaters consist of debt instruments whose yields rise as short-term rates fall, and vice versa. Inverse floaters act like very long-term bonds.

\section{Some Rationales for Issuing SFAS No. 119 and Other Future Authoritative Pronouncements on This Issue}

Given the importance of accounting properly for derivatives, financial analysts, the business press, the SEC and others mandate that entities, their auditors and financial statement users and preparers monitor such transactions and their financial controls most carefully by focusing on such issues as:

- Off-balance-sheet nature. Since derivatives contracts often occur with little or no cash changing hands, reported amounts may not indicate the full extent of an entity's involvement. Moreover, without necessary controls to record changes in value, significant unrecorded gains and losses can go undetected.

- Complexity. An entity may misunderstand the actual terms and effects of a particular derivative contract, including how it uses a particular financial instrument, how to value and account for it and whether it achieves its desired economic objectives. 
- Leverage. Derivatives create new opportunities to increase significantly financial leverage. For example, leveraged interest rate swaps that require interest payments of multiples of changes in a specified market rate sharply expose an entity to potential losses disproportionate to interest rate changes.

- Non-liquidity. Since derivatives markets may not be liquid (i.e., "easily" marketable), problems exist in valuing current instruments and their exit (e.g., fair market) values.

- Unclear accounting and tax rules. Designers of complex financial instruments often try to utilize perceived market anomalies, since current tax and accounting rules generally have not kept pace with the rapid development of new derivatives products and uses.

- Legal risk. Some entities have been unable to enforce the terms of derivatives contracts against counterparties - such as government agencies or companies in a regulated industry - that do not have the authority to enter into the transaction or lack adequate or clear documentation of contract terms. Enforceability risks are heightened with foreign counterparties and may not come to light until the counterparties" credit deteriorates or bankruptcy or insolvency occurs.

- Operational and control risk. A company's treasury department often originates derivatives transactions, sometimes without coordinating them with those responsible for recording the transaction and the financial and tax reporting.

\section{SFAS No. 119}

In response to the above-named objectives, SFAS No. 119's provisions require disclosing a financial instrument's face or contract amount, the instrument's nature and terms (incorporating a discussion of its credit and market risks), cash requirements of such instruments and related accounting policies. Derivatives classified as held or issued for trading purposes should disclose the average and related end-of-period fair value, any net gains or losses from the trading activities, and the location in the financial statements of the gains or losses. Derivatives classified as held or issued for purposes other than trading require a description of the entity's objectives for holding or issuing such derivatives and a description of how the derivative and related gains or losses are reported, in addition to their location in the financial statements. Based upon a reading of many annual reports, Exhibit 1 presents two examples of "model" footnote disclosure taken from 1995 annual reports. However, SFAS No. 119 recommended - but did not require - making quantitative disclosures concerning interest rate, foreign exchange, commodity price or other market risks, causing major concern at the SEC as discussed below. For example, Wooley (1997) notes that Sears' 1996 financial statement discloses a $\$ 382$ million loss from derivative holdings in its footnotes but does not indicate the source or disposition of this major item. 


\section{Exhibit 1 \\ Disclosure Examples of Financial Instruments}

\section{McDonald's Corporation \\ Financial Instruments}

The Company utilizes derivatives in managing risk, but not for trading purposes. NonU.S. Dollar financing transactions generaily are effective as hedges of either long-term investments in or intercompany loans to foreign subsidiaries and affiliates. Foreign currency gains and losses on the hedges of long-term investments are recorded as foreign currency translation adjustment included in shareholders' equity. Gains and losses related to hedges of intercompany loans offset the gains and losses on intercompany loans and are recorded in nonoperating income (expense).

Interest-rate exchange agreements are designated and effective to modify the Conpany's interest-rate exposures. Net interest is accrued as either interest receivable or payable with the offset recorded in interest expense. Gains or losses from the early termination of interest rate swaps are amortized as an adjustment to interest expense over the shorter of the remaining life of the swap or the underlying debt being hedged.

The Company also purchases foreign currency options (with little or no intrinsic value) to hedge future foreign currency-denominated royalty and other payments received in the U.S. The premiums paid for these options are amortized over the option life and are recorded in nonoperating expense. Any realized gains on exercised options are deferred and amortized over the period being hedged.

Short-term forward foreign exchange contracts are also used to mitigate exposure on foreign currency-denominated cash flows received from affiliates and subsidiaries. These contracts are marked to market with the resulting gains or losses recorded in nonoperating income (expense). Gains and losses associated with these forward contracts have not been material.

If a hedged item matures or is extinguished, the associated derivative is marked to market with the resulting gain or loss recognized immediately. The derivative then is redesignated as a hedge of some other item or terminated.

The carrying amounts for cash and equivalents and notes receivable approximated fair value. No fair value was provided for noninterest-bearing security deposits by franchisees as these deposits are an integral part of the overall franchise arrangements.

\section{General Motors}

Note 11. Fair Value of Financial Instruments

In accordance with the requirements of SFAS No. 107, Disclosures about Fair Value of Financial Instruments, and SFAS No. 119. Disclosures about Derivative Financial Instruments and Fair Value of Financial Instruments, General Motors has provided the following fair value estimates and information about valuation methodologies. The estimated fair value amounts have been determined using available market information or other appropriate valuation methodologies. However, considerable judgment is required in interpreting market data to develop estimates of fair value; therefore, the estimates are not necessarily indicative of the amounts that could be realized or would be paid in a current market exchange. The effect of using different market assumptions and/or estimation methodologies may be material to the estimated fair value amounts.

Fair value information presented herein is based on information available at December 31, 1995 and 1994. Although management is not aware of any factors that would signifi- 


\section{Exhibit 1 \\ Disclosure Examples of Financial Instruments cont'd}

cantly affect the estimated fair value amounts, such amounts have not been updated since those dates and, therefore, the current estimates of fair value at dates subsequent to December 31, 1995 and 1994 may differ significantly from these amounts. The estimated fair value of financial instruments held by General Motors, for which it is practicable to estimate that value, are set forth below:

\begin{tabular}{lrrrrr} 
& \multicolumn{5}{c}{ December 31 } \\
& \multicolumn{4}{c}{1995} & \multicolumn{2}{c}{1994} \\
& \multicolumn{1}{c}{ Book } & \multicolumn{1}{c}{ Fair } & Book & Fair \\
(Dollars in Millions) & Value & Value & Value & Value \\
Assets & & & & \\
$\quad$ Cash and Marketable Securities & $\$ 16,642.9$ & $\$ 16,642.9$ & $\$ 16,075.6$ & $\$ 16,075.6$ \\
$\quad$ Finance Receivables - net & $58,714.8$ & $59,095.9$ & $54,048.4$ & $53,869.8$ \\
Accounts and Notes Receivable - net & $9,946.2$ & $9,946.2$ & $\mathbf{8 , 7 4 2 . 5}$ & $8,742.5$
\end{tabular}

\section{SEC's New Disclosure Requirements}

While many financial statement users consider the FASB's new disclosure provisions regarding derivative financial instruments more than adequate, the SEC requires publicly traded companies to make even further disclosures. Spurred by the recommendations of the American Institute of CPA's Special Committee on Financial Reporting, the Federal Reserve Bank of New York and a task force of the Financial Executives Institute, the SEC staff reviewed over five-hundred 1994 and 1995 annual reports which showed that many entities inadequately reported how derivatives affected such reported items as commodity positions, firm commitments and other anticipated transactions. These omissions could impair financial statement users from effectively predicting expected future cash flow streams of such items as how financial derivatives impact the repricing characteristics of certain debt obligations.

Thus, the SEC's new requirements clarify and expand existing footnote disclosures regarding derivative financial instruments by requiring disclosures outside the financial statements about market risk inherent in derivative and related financial instruments. The SEC allows companies some flexibility in disclosing quantitative information by choosing from three disclosure alternatives, thereby allowing registrants to disclose the information to best reflect the degree of market risk inherent in their activities. 


\section{Additional Disclosures}

To supplement the requirements of SFAS No. 119, the SEC required that publicly traded companies with material amounts of derivatives should disclose in their footnotes:

1. All methods used to account for derivative financial instruments;

2. Types of derivatives (e.g., interest rate floors) accounted for under each method;

3. Criteria required to be met for each accounting method (e.g., the company will recognize revenues if such stated criteria are met);

4. The accounting method used if the specified criteria are not met;

5. Accounting for the termination of derivatives designated as hedges or otherwise used to affect other financial instruments (e.g., to balance out expected cash flows);

6. Accounting for derivatives if the designated item matures, is sold, terminated or the related, anticipated transaction is no longer likely to occur; and

7. Where and when derivatives and their related gains and losses are reported in the balance sheet, income statement and statement of cash flows.

Furthermore, registrants should distinguish between accounting policies adopted for derivatives used for trading and other (e.g., speculative) purposes.

\section{Disclosures of Quantitative and Qualitative Information About Market Risk}

Registrants with material amounts of market risk sensitive financial instruments or who face potentially material losses from reasonably possible market movements, would prepare a new Disclosure Section outside the basic financial statements that discusses certain quantitative and qualitative aspects of market risk. Small business issuers must also consider making such disclosures in the Management Discussion \& Analysis (MD\&A) requirements in their SEC filings to the extent that market risk represents a materially known trend, event or uncertainty. Specifically as shown in Exhibit 2, registrants would select one of three quantitative disclosure methods (i.e., tabular presentation of expected cash flows, sensitivity analysis or value at risk) and highlight qualitative disclosures of market risk, focusing on how the entity manages those exposures (e.g., describing the general objectives of holding such financial instruments and strategies used to manage these risks). 


\section{Exhibit 2 \\ Proposed Additional SEC Disclosure Requirements}

\section{Type of Disclosure}

(1) Quantitative Disclosure

\section{Summary Requirements}

Outside the basic financial statements, chose one of three alternatives:

\section{- Tabular Presentation}

Show instruments' fair values, expected cash flows and weighted average effective rates or prices.

Summarize by used exposure category (e.g., interest rate used, foreign curtency exchange rate used, commodity price risk or equity price risk).

Group instruments by common characteristics.

\section{- Sensitivity Analysis}

Disclose potential losses in future earnings, fair values or cash flows of market risk sensitive instruments.

\section{- Value at Risk}

Show potential entity-wide loss in flow values, cash or earnings of market risk sensitive instruments.

Disclosure Required outside basic financial statements

Show by category primary market risk exposure and any changes in market risk exposure.

Disclose how exposures to market risk are managed.

(3) Accounting Policy

Disclose each method used to account for derivatives and criteria required to use each method.

Show types of derivatives used under each method.

First, the tabular presentation would require quantitative information containing common inputs to market risk measurements and, thus, provide additional information of the registrant's exposure to market risk. Registrants would summarize this tabular information by risk exposure category (c.g., interest rate, foreign currency and commodity price risk), and the foreign exchange rate risk category should be further subdivided by functional currency (e.g., Japanese yen or 
U.S. dollar). Entities should also group such instruments by common risk exposure characteristics. Thus, a registrant would disclose in the interest rate exposure category such items as fixed rate Mexican peso investments, variable rate French franc debt obligations or long U.S. Treasury futures. They would report for each instrument in the table, separate expected principal or cash flow information for each of the next five years, with any remaining, expected cash flows presented separately as an aggregate amount.

Next, registrants disclosing hypothetical losses in future earnings, cash flows or fair values of market risk sensitive instruments using sensitivity analysis would make separate disclosures for interest rate, currency exchange rate, certain commodity price and other types of sensitive instruments. To provide further information about the sensitivity of the instruments' assumptions and parameters, registrants also should disclose (a) how they define such losses (e.g., lost earnings or cash flows), (b) the general modeling technique (e.g., changes in net present values arising from parallel shifts in market rates), (c) the general types of instruments covered by this model (e.g., derivative commodity instruments) and (d) other relevant information on the model's parameters (e.g., prices used for each category of market risk exposure and how discount rates are determined).

Entities selecting the third alternative would show adverse market conditions by disclosing separately interest rate, currency exchange rate, certain commodity price and other types of sensitive instruments. They would also show for the current period either the (a) average or range in value at risk amounts, (b) average or range in actual changes in fair values or (c) percentage of actual changes in fair values, earnings or cash flows from market sensitive instruments that exceed the reported value at risk amounts.

To provide additional qualitative disclosures, entities would describe how they evaluate material changes in their primary risk exposures and material changes in managing material risks to those exposures. They should also compare changes in these items from prior periods and discuss expected effects in future periods. These provisions would apply both to derivative financial instruments and to other related items including derivative commodity instruments, commodity positions and expected cash flows from anticipated transactions. To encourage companies to disclose this forward-looking information, the SEC grants them safe harbors from many unwarranted legal actions (as provided by the recently passed Private Securities Litigation Reform Act of 1995).

The SEC contends further that qualitative disclosures complement quantitative disclosures by placing risk management activities in perspective. Since SFAS No. 119 qualitative disclosures apply only to certain derivatives held or issued for purposes other than trading, the SEC requires expanded disclosure by creating a new Item 305 (b) of Regulation S-K. Here an entity would present narrative disclosures that would occur outside the basic financial statements and include primary market risk exposures and how these exposures are managed by the entity. Registrants would disclose their primary market risk exposure at the end of the 
reporting period and how they manage those risks, as well as discuss material changes in how those risks are managed when compared to the most recent reporting period. Such qualitative disclosures would be presented separately for instruments entered into for trading and nontrading purposes.

Entities must also disclose "material" market risk based upon two key factors: (1) the materiality of the fair values of the disclosed instruments outstanding at the end of the current reporting period, and (2) the materiality of any potential loss predicted for any reasonably possible market movements. If either is material, they must disclose both qualitative and quantitative information concerning market risk.

Entities should also place such disclosures outside the financial statements; they therefore would not be covered by the independent auditor's opinion. Finally, entities should consider the potential duplication of disclosures required by the current MD\&A requirements and the proposed rules in the new Item 305. The SEC concludes that registrants currently disclosing the impact of known uncertainties in its MD\&A or in other financial statement footnotes, need not report such duplicate information in its SEC filings.

\section{FASB Accounting Requirements for Hedging and Derivatives}

To blunt some SEC criticism and to provide additional information to financial statement users, in June 1996 the FASB issued an Exposure Draft to help "improve" how entities account for derivatives (Cheney, 1997) which ultimately became SFAS No. 133. Now, derivatives are valued at current market prices, but also encompass changes in the values of the underlying financial instruments - thereby minimizing fluctuations in the values of these financial instruments. Basically, the new statement requires that all derivatives be carried on an entity's balance sheet as either assets or liabilities at fair or market value. Gains or losses in the fair values of derivatives are accounted for based on the derivatives' designation. Entities designating derivatives as hedges of cash flow exposure of a forecasted transaction defer changes in fair value as a component of comprehensive income and recognized in earnings when the transaction is projected to occur. For all other derivatives, the change in fair value is recognized as a gain or loss in the current income statement.

The FASB found that derivatives are either assets or liabilities and, thus, should be recorded and reported in the financial statements. Such financial instruments should be measured at fair value, which the Board determined is the only relevant measure for derivatives since fair value is useful and understandable to financial statement users. During the discussion period, however, 13 chief executives of major banks and other large corporations (Cheney, 1997) informed the FASB, the SEC and Federal Reserve Chair Greenspan that the FASB's then proposed additional qualitative disclosures could cause "incorrect valuations" of equity investments. Similarly, the Institute of Management Accountants (IMA) (Rogero, 1996) also protested these new qualitative disclosures and asked that the relevance of management be allowed to disclose its market risk in any way it sees fit. 
Several empirical studies have found inefficiencies in the pricing of financial derivatives and their associated, underlying financial securities. Jordan and Kuipers (1997) derived direct evidence that derivative assets can significantly distort efficient pricing in the primary asset market; and Sim and Thurston (1996) found some market inefficiencies in the relation between the yield-to-maturity and timeto-maturity of default-free pure discount bonds, and the price and hedge interest rates of derivative financial instruments. Such market inefficiencies suggest that the relevance of viewpoints of users and preparers of financial instruments should play a key role in developing new rules to account for such financial instruments.

\section{Empirical Study}

\section{Methodology}

To explore how key constituencies view derivative financial instruments, we surveyed four major groups who must implement any new Standards: CPAs who specialize in auditing publicly-traded financial institutions; bank accounting executives (AE) of financial institutions selected from Faulkner \& Gray's Bank Accounting \& Auditing Executives Data Base; management accountants (MA) working for financial institutions, selected from the IMA's Membership List; and financial analysts (FA) selected from 1995 Membership Directory published by the Association for Investment Management and Research. The 400 questionnaires were sent to 100 members from each group.

After reviewing current and proposed standards for derivatives and Mahoney and Kawamura's (1995) study of derivative disclosures for the FASB, we developed a preliminary survey instrument, which was then pretested and revised based upon the comments of five academicians, six CPAs, five financial officers and four management accountants. The questionnaire addressed three main areas relating to accounting for derivatives:

1. Questions relating to financial reporting and economic reality;

2. Questions relating to entities' decision making capabilities; and

3. Questions relating to potentially "manipulating" financial information or statements.

The final questionnaire appears as Exhibit 3.

To garner a high response rate, we hand-signed all correspondence, used four waves of response requests, including pre-notification letters, and applied postage stamps on envelopes both to and from the respondents. We received 176 usable responses (responses from $40 \mathrm{CPAs}, 44 \mathrm{AEs}, 47 \mathrm{MAs}$ and $45 \mathrm{FAs}$ ), an overall $44 \%$ response rate.

Even with a relatively high response rate, tests were made for non-response bias using (1) the early-late hypothesis (Oppenheim, 1966), and (2) a comparison of known characteristics of respondents and non-respondents (Ferber, 1948). The results indicate no significance $(\mathrm{p} .<.05)$ differences between early and late respondents, suggesting strongly that no significant non-response bias occurred. 


\section{Exhibit 3 \\ Summary of Questionnaire Used in Survey}

Please indicate the extent to which you agree or disagree to the following statements.

Strongly Agree Neither Strongly Agree nor Disagree Strongly Disagree

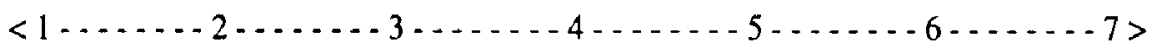

1. Do disclosures required by SFAS No. 119 disclose adequately current derivative activities?

2. Do the provisions of SFAS No. 119 cause companies to report financial derivatives to "manipulate income rather than report economic reality?"

3. The SEC has proposed increasing the disclosure requirements of accounting for certain derivative instruments. Should the scope of such new disclosures primarily be limited to publicly traded companies?

4. Will such additional SEC disclosures for derivatives add "critical information" for investment purposes?

5. Will such additional SEC disclosures for derivatives add "critical information" for lending/credit purposes?

6. Should the SEC require entities to disclose "material" changes in the fair values of derivative activities measured both at the end and during each reporting period?

7. Should entities be allowed to choose one of three ways to present quantitative information about market risk: tabular presentation of expected future cash flows and terms, sensitivity analysis or value at risk?

8. The SEC proposes that entities disclose quantitative information about general market risk to help indicate the level of market risk from normal market movements. Should it also require estimating market risk inherent in unusual markets reflecting worst-case scenarios?

9. The SEC recognizes that the proposed disclosures may be complex, especially in requiring the describing of the model and key assumptions used to prepare quantitative disclosures about market risk. Given this complexity, should the proposed information disclose market risk in reports and statements filed with the SEC that are not required to be delivered to all shareholders and investors?

10. Should small business issuers be excluded from part of proposed quantitative and qualitative disclosures of market risk? 
A seven-point Likert scale ( 1 indicating agreement and 7 disagreement) was used by the respondents to indicate their degree of agreement or disagreement to questions addressing the key issues. While the question form ordinarily suggests a "yes" or "no" answer, the Likert scale allows a continuum of strongly agree to strongly disagree responses.

\section{Results and Observations}

Sample Mean Responses are summarized and shown in Table 1, with paired comparison tests, ANOVA and Scheffe's test results shown in Table 2. Where the ANOVA indicated significant differences (p.<.05) among mean responses of the various treatment groups, Scheffe's multiple comparison test was used to determine which groups had statistically significant differences. The results show that all four groups generally agree with the provisions of SFAS No. 119 (Question No.1), and most favor the increased reporting standards (Questions 4-9). MAs were mostly indifferent (3.75) to the SEC proposal of using only three qualitative methods to disclose market risk (Question No. 7) - despite the IMA's "strong" letter to the contrary [Rogero, 1996]. However, only two sets of significant differences among the four groups of respondents arose. Regarding Question Nos. 4 and 5, FATs with mean responses of 3.41 and 3.21 generally considered the SEC proposals to add "critical information" for investment and lending purposes more cost-beneficial than did the other three groups (CPAs: 1.95 and 1.87; FEs: 2.16 and 2.07; and MAs: 2.05 and 1.95, respectively). Thus, the groups are nearly unanimous in their evaluations of the three areas of questions, indicating that they generally believe that the SEC statement will enhance economic reality and increase the reliability and relevance of financial reporting. These results also indicate support of the main provision of SFAS No. 133.

While the survey instrument gave many details of the new Standards on derivatives, some respondents may have been unfamiliar with the relevant details of the pronouncements. This limitation could weaken the generalizability of the findings. Furthermore, as the respondent groups gain experience from using financial derivatives, their viewpoints may change.

\section{Conclusions}

The FASB's and SEC's current standards seek to improve financial reporting for derivatives and other financial instruments, thereby increasing the visibility, comparability and understandability of risks associated with such instruments. Given the magnitude of this issue, corporate controllers and financial executives should plan now to understand and implement these new accounting requirements and, thus, provide fuller disclosure to their financial statement users. 
Table 1

\section{Mean Responses of Groups Surveyed*}

Questions

\author{
Certified \\ Public
}

Accountant

(40)

[Group 1]

Q1

Q2

Q3

Q4

Q5

Q6

Q7

Q8

Q9

Q10

6.21
Bank

Financial

Executive

(44)

[Group 2]

2.35

2.17

2.61

2.71

4.12

3.41

3.21

2.26

1.27

1.31

1.27

1.35

3.75

3.15

3.20

2.15

2.14

2.02

1.82

1.75

1.68

1.62

6.51

6.17

6.33

* Scaling and Other Notes

1. Values represent a 7 -point scale $(1=$ strong agreement through $7=$ strong disagreement with the statement).

2. A summary of the questions is found in Exhibit $I$.

3. If significant differences using one-way analysis of variance $(p .<.05)$ in the response patterns between at least two groups were noted, Scheffe's multiple comparison test was used to determine which groups had statistically significant weaknesses.

4. The responses to questions 4,5 and 7 indicated such significant differences, with the results appearing in Table 2. 
Table 2

Scheffe Pairwise Comparison Test Results

$\begin{array}{cccc}\begin{array}{c}\text { Question } \\ \text { Number }\end{array} & \text { Groups } & \begin{array}{c}\text { Group } \\ \text { Means }\end{array} & \begin{array}{c}\text { Group } \\ \text { Differences }\end{array} \\ \text { Q4 } & 4 & 3.41^{*} & \\ & 2 & 2.16 & 1,2 \text { and } 3>4 \\ & 3 & 2.05 & \\ \text { Q5 } & 1 & 1.95 & \\ & 4 & 3.21^{*} & 1,2 \text { and 3 }>4 \\ & 2 & 2.07 & \\ \text { Q7 } & 3 & 1.95 & \text { No differences } \\ & 1 & 1.87 & \text { among groups } \\ & 3 & 3.75 & \\ & 2 & 3.15 & \\ & 4 & 3.15 & \end{array}$

\section{NOTES}

1. Abbreviations for groups presented in the above Table: (1) Certified Public Accountants; (2) Bank Financial Officers; (3) Management Accountants; and (4) Financial Analysts

2. (*) Denotes pairs of groups significantly different at the 0.05 level of significance.

3. Scheffe's test performed on questions which exhibited significant differences in means between groups in the ANOVA tests.

\section{References}

Barrett, A. \& Zweig, P.L. (1994). Managing risk, Business Week, (October 31), 86-104.

Cheney, G. (1997). Bankers battle tenaciously to block FASB on derivatives, Accounting Today, (October 3), 4, 61 .

Ferber, R. (1948). The problem of bias in mail returns: A solution, Public Opinion Quarterly, 669-676.

Financial Accounting Standards Board (1981). Statement of Accounting Standards (SFAS) No. 52, Foreign currency translation, Stanford, CT: FASB.

SFAS No. 80, (1980). Accounting for futures contracts.

SFAS No. 105 (1990). Disclosure of information about financial instruments with off-balance sheet risk and financial instruments with concentrations of credit risk. 
, SFAS No. 107 (1991). Disclosures about fair values of financial instruments.

SFAS No. 115 (1993). Accounting for certain investments in debt and equity securities.

, SFAS No. 119 (1994). Disclosure about derivative financial instruments and fair value of financial instruments.

SFAS No. 133 (1998). Accounting of derivative instruments and hedging activities.

Mahoney, J.P. \& Kawamura, Y. (1995). Review of 1994 disclosures about derivative financial instruments. Norwalk, CT: FASB Special Report No. 156-A.

Oppenheim, A.N. (1966). Questionnaire design and attitude measurement, New York: Basic Books.

Rogero, L.H. (1996) (Chair, Financial Reporting Committee, Institute of Management Accountants). Letter to the securities and exchange commission, (May 13).

Securities and Exchange Commission (1995). Proposed amendments to require disclosure of accounting policies and qualitative market risk information inherent in financial instruments" File \#S7-35-95, Washington, DC: SEC (December 28).

Securities and Exchange Commission (1977). General report release (FRR) No.48, Disclosure of financial policies, Washington, DC: SEC (January).

Sim, A.B. \& Thurston, D.C. (1996). An empirical study of a new class of no-arbitragebased discrete models of the term structure, Journal of Financial Research, (Winter), 493-513.

Wooley, S. (1997). Night baseball...without lights, Forbes, (August 11), $42-43$. 